\title{
Pronaf Jovem: as disjunções entre o ideal e o real
}

\author{
Pronaf Jovem: the disjunctions between the ideal and the real \\ Joel Orlando Bevilaqua Marin' ${ }^{1}$ (B) \\ 'Programa de Pós-graduação em Extensão Rural, Universidade Federal de Santa Maria (UFSM), Santa Maria (RS), \\ Brasil. E-mail: bevilaquamarin@gmail.com
}

Como citar: Marin, J. O. B. (2020). Pronaf Jovem: as disjunções entre o ideal e o real. Revista de Economia e Sociologia Rural, 58(2), elocation. https://doi.org/10.1590/1806-9479.2020.187438

\begin{abstract}
Resumo: O artigo analisa, a partir de contrapontos entre princípios normativos e experiências vividas por jovens rurais, os limites do Pronaf Jovem na construção social de uma juventude rural sucessora na agricultura familiar. A pesquisa combinou levantamento documental e estudo de caso. No estudo de caso, realizado em municípios da Região Central do Rio Grande do Sul, foram produzidos dados qualitativos e quantitativos. O Pronaf Jovem idealiza a construção de uma juventude rural autônoma, pluriativa, integrada em instituições de desenvolvimento rural e sucessora na agricultura familiar. Na realidade pesquisada, os jovens rurais não conseguiram acessar crédito rural na linha Pronaf Jovem. Eles investem em diferenciadas estratégias de emancipação pessoal, que raramente se encaminham pelos projetos de sucessão hereditária na agricultura familiar.
\end{abstract}

Palavras-chave: juventude rural, agricultura familiar, Pronaf Jovem, crédito rural.

\begin{abstract}
This article analyzes the limits of Pronaf Jovem in the social construction of a successor rural youth in family farming from counterpoints between normative principles and experiences lived by young rural people. The research data were obtained by combining documentary research and case study. The case study was carried out in municipalities of the Central Region of Rio Grande do Sul, it was produced qualitative and quantitative data. Pronaf Jovem idealizes the construction of an autonomous, pluriactive rural youth, integrated in institutions of rural development and successor in family farming. In this study, rural youth could not access rural credit through Pronaf Jovem. They invest in differentiated strategies for personal emancipation, which are rarely directed towards projects of hereditary succession in family farming.
\end{abstract}

Keywords: rural youth, family farming, Pronaf Jovem, rural credit.

Introdução

A partir de 2003, a juventude rural tornou-se beneficiária do Pronaf Jovem, uma linha do Programa Nacional de Fortalecimento da Agricultura Familiar (Pronaf). Essa política de crédito destina-se, especificamente, aos jovens rurais de ambos os sexos, integrantes de unidades produtivas categorizadas como agricultura familiar. Em seus princípios norteadores, o Pronaf Jovem idealiza criar alternativas produtivas geradoras de renda, facilitar a permanência no meio rural, construir processos de autonomia financeira e melhorar a qualidade de vida pela interligação da juventude rural aos mercados, ao sistema bancário e às redes de instituições de desenvolvimento rural. Porém, em termos práticos, essa linha de crédito tem sido acessada por um número muito restrito de jovens rurais, o que indica a existência de diversos fatores que impossibilitam sua objetivação na realidade social.

Neste artigo, analiso as disjunções entre idealizações expressas nas normativas do Pronaf Jovem e experiências vividas por jovens rurais, para evidenciar as limitações dessa política pública na viabilização de processos de inserção produtiva da juventude rural e de sucessão hereditária na agricultura familiar. A fim de não cair em generalizações que 
subtraem as possibilidades de compreensão das particularidades de processos sociais, o estudo foi realizado com jovens rurais que vivem em municípios da Região Central do Rio Grande do Sul.

A pesquisa foi construída a partir da combinação de pesquisa documental e estudo de caso. A análise documental, segundo Cellard (2010), tem sido privilegiada pelos historiadores, mas pesquisadores de outras áreas das Ciências Sociais também utilizam documentos como fonte preciosa para análise de fenômenos sociais. Mas o referido autor adverte que é necessário proceder à análise do contexto histórico-social em que o documento foi escrito, os interesses manifestos ou subjacentes do autor ou autores do documento e os conceitos e lógica interna do documento. Nesta pesquisa, a análise documental não pretende uma investigação do tipo historiográfico, mas um procedimento metodológico pontual destinado a evidenciar concepções e processos de produção de determinado tipo de sociedade, no caso específico, um estereótipo de juventude rural delineado nas diretrizes normativas do Pronaf Jovem.

Com base nessas orientações, procurei evidenciar as idealizações sobre a juventude rural, delineadas nos diversos critérios normativos para enquadramento da contração de crédito rural. Para tanto, valorizei as diretrizes da normatização do Pronaf Jovem, especialmente as publicadas no Plano Safra 2015/2016, embora Planos Safras de anos anteriores também sejam referenciados quando considerados necessários para a compreensão. Ademais, recorri aos registros escritos produzidos por mediadores sociais vinculados às instâncias governamentais e comprometidos com as causas da juventude rural.

Enquanto, no levantamento documental do Pronaf Jovem, priorizei a análise das idealizações sobre a juventude rural, no estudo de caso valorizei aspectos da realidade social de jovens rurais. O estudo de caso foi realizado com jovens rurais residentes em municípios da Região Central do Rio Grande do Sul ${ }^{1}$, no âmbito de um projeto de extensão universitária desenvolvido em parceria entre a Emater/RS, Universidade Federal de Santa Maria (UFSM) e Instituto Federal Farroupilha (IFF), no qual participei desde a concepção do projeto até a redação final do relatório. A participação nas diversas etapas desse projeto de extensão universitária, que resultou no documento intitulado Juventude Rural: Estudo no Território Região Central do Rio Grande do Sul (Picolotto \& Marin, 2018), possibilitou-me a compreensão das limitações da implantação, em termos práticos, do Pronaf Jovem na Região Central do Rio Grande do Sul.

O estudo de caso priorizou a produção de dados qualitativos e quantitativos. Para efeitos de amostragem, foram considerados "jovens rurais" os sujeitos sociais integrantes de famílias de agricultores, com idades de 16 a 29 anos - faixa etária na qual, legalmente, podem contrair crédito na linha Pronaf Jovem. As entrevistas, com vistas a produzir dados qualitativos, foram orientadas por um roteiro de questões semiestruturadas, no esforço de aprofundar aspectos das relações de jovens rurais com o Pronaf Jovem, no que tange ao desenvolvimento de atividades produtivas e vinculações no mercado, nas instituições de desenvolvimento rural e no sistema bancário. Para tanto, foram selecionados, segundo critérios não probabilísticos, doze jovens rurais² ${ }^{2}$, sendo quatro rapazes e oito moças, a partir da mediação de agentes de serviços de assistência técnica e extensão rural. O número de jovens entrevistados foi definido pelo critério de "saturação empírica" (Pires, 2010). Dessa forma, a finalização das entrevistas ocorreu quando os últimos dados coletados não aportavam mais informações suficientemente novas ou diferentes. Os jovens rurais entrevistados residiam em cinco municípios da referida Região: Agudo, Júlio de Castilhos, Tupanciretã, Mata, Jari e Toropi. No momento da entrevista, sete jovens rurais eram solteiros e cinco, casados; sete trabalhavam na agricultura familiar, duas jovens (sexo feminino) trabalhavam como assalariadas e três jovens continuavam os estudos escolares, sendo um no ensino médio e dois no ensino superior.

\footnotetext{
1A Região Central do Rio Grande do Sul, com uma área de 32.457,00 km², é constituída por 34 municípios. Em 2010, a população total da Região era de 647.769 habitantes, sendo que 19,44\% viviam no meio rural. (Brasil, 2016a).

${ }^{2}$ Com a finalidade de preservar o anonimato dos jovens rurais entrevistados, os nomes utilizados na pesquisa são fictícios.
} 
Os dados quantitativos foram obtidos por meio de questionários dirigidos a jovens rurais com idades de 16 e 29 anos, residentes em munícipios da Região Central do Rio Grande do Sul: Dilermando de Aguiar, Nova Esperança do Sul, Nova Palma, Silveira Martins, Restinga Seca, Dona Francisca, Mata, Cacequi, Quevedos, Agudo, Toropi, Unistalda, Tupanciretã e Jari. Nesses municípios, segundo dados do IBGE de 2010, a população rural com idades entre 16 e 29 anos era de 8.046 pessoas, sendo 4.200 do sexo masculino e 3.846 do sexo feminino (Instituto Brasileiro de Geografia e Estatística, 2010). A amostragem foi constituída por 191 jovens rurais, representando, portanto, 2,37\% do total da população juvenil rural. A amostragem foi do tipo intencional, seguindo os seguintes critérios: a) filhos de agricultores familiares; b) faixa etária entre 16 e 29 anos; c) distribuição equitativa entre os sexos; d) facilidades de acessos aos jovens rurais. Na obtenção de maiores facilidades de acessos aos jovens rurais, foram consideradas as indicações de técnicos vinculados à Emater/RS, que tinham prévios conhecimentos e atuações junto às famílias dos jovens rurais. Dessa forma, do total de 191 jovens respondentes do questionário, 51\% eram do sexo masculino e $48 \%$ do sexo feminino, $76 \%$ solteiros e $24 \%$ casados, $53,0 \%$ estudavam e $47,0 \%$ não estudavam.

Para fins de organização deste artigo, na primeira seção, apresento processos de institucionalização do Pronaf Jovem com vistas a evidenciar as idealizações sobre a juventude rural brasileira vinculada à agricultura familiar. Nas quatro seções subsequentes, a partir de contrapontos entre os ideais expressos nos critérios do Pronaf Jovem e as experiências vividas por jovens rurais gaúchos, analiso os contraditórios processos sociais de produção de uma juventude rural autônoma, pluriativa, integrada em instituições de desenvolvimento rural e vinculada ao sistema bancário.

Pronaf Jovem: a construção da juventude rural sucessora na agricultura familiar

O Pronaf Jovem Rural, criado no Plano Safra 2003/2004, apresentou como especificidade a introdução de um recorte geracional no escopo da política de crédito rural, com significados importantes para o reconhecimento da juventude rural como categoria social portadora de direitos ao financiamento creditício. Caracteriza-se por ser uma política pública destinada a produzir condições objetivas e subjetivas para viabilizar processos de sucessão hereditária na agricultura familiar. A juventude rural torna-se, portanto, uma categoria social destinada a dar continuidade ao mundo rural e à reprodução social do campo e, mais especificamente, à agricultura familiar.

De acordo com Feixa (2004, 2006), a compreensão da juventude como uma categoria social requer a análise dos diferentes contextos econômicos, históricos, sociais e culturais em que os jovens vivem. As sociedades construíram, ao longo dos processos de desenvolvimento, diferentes maneiras de perceber e inserir os jovens, definindo-lhes papéis, funções e espaços institucionais considerados adequados de socialização. À medida que as sociedades mudam, processam-se também mudanças nas instituições, nas políticas e nas imagens de juventude. As juventudes tornam-se, portanto, uma metáfora sociocultural, que permite visualizar as sociedades em mudanças e analisar as transformações sociais estabelecidas para os jovens ou mesmo pelos jovens. As instituições de socialização, assim com as políticas juvenis, traduzem processos de construções de juventudes modernas pelo enquadramento social dos jovens e pela transmissão de coisas, saberes, habilidades e técnicas, sendo, portanto, produtoras de diferenciadas concepções de juventudes e projetos de desenvolvimento social.

Sob essa perspectiva, segundo Feixa $(2004,2006)$, não existe uma única forma de ser jovem, mas uma multiplicidade de maneiras de entender-se, de expressar-se e de viver-se a juventude. Todavia, para que haja reconhecimento da juventude como uma fase específica da vida, deve existir uma série de condições sociais, ou seja, "normas, comportamentos e instituições que distingam os jovens de outros grupos de idade" (Feixa, 2006, p. 28). As instituições sociais, conforme Urteaga (2011), constroem socialmente sua juventude à medida que estruturam as condições de existência dos jovens e transmitem as representações dominantes sobre o juvenil. Dentro delas, os jovens internalizam e reproduzem a realidade social. Portanto, as instituições servem para "assinalar as normas 
de conduta, valores, espaços, papéis e imagens específicas para sua juventude e para 'definir', em termos materiais e simbólicos, as maneiras de ser jovem", contribuindo para o enquadramento das ações e ideias das gerações juvenis (Urteaga, 2011, p. 36).

Contudo, as instituições que se ocupam da socialização da juventude também produzem discursos e imagens de representação do que deve ser jovem. Essas imagens juvenis estão associadas à subjetividade e fazem referência a valores, símbolos, atributos e ritos, necessários ao enquadramento social das jovens gerações. A partir do estudo da juventude mexicana, Urteaga \& Pérez (2004, p. 185) afirmam:

[...] as representações institucionais sobre o juvenil se constroem, principalmente, ainda que não exclusivamente, de uma ideação no sentido de uma reconstrução simbólica de um dever ser jovem, extraído do projeto da nação ou do modelo de desenvolvimento e do lugar/papel que a sociedade espera que um jovem cumpra.

Dessa forma, as instituições sociais e as políticas juvenis produzem condições sociais e imagens culturais, que sinalizam os caminhos e os meios reconhecidos para os jovens qualificarem-se e, no futuro, adentrar no mundo adulto. O Pronaf Jovem, como política pública, prevê a articulação de uma série de instituições de desenvolvimento rural, sejam públicas ou privadas, ao mesmo tempo em que engendra uma ideação dos papéis da juventude rural na sociedade e dos espaços sociais que os jovens devem ocupar nos processos de desenvolvimento rural. As idealizações são, portanto, representações socialmente construídas sobre a juventude rural, que projetam expectativas dos papéis sociais atribuídos aos jovens.

As idealizações podem ser apreendidas a partir das diretrizes normativas do Pronaf Jovem, na medida em que definem os critérios enquadramento social dos jovens. As ideações são projetadas no sentido de criar condições para que os jovens acessem tecnologias e conhecimentos, interconectem-se com instituições financeiras, educativas e integrem-se aos mercados de trocas de bens e serviços. O ideal fundamental é produzir condições sociais favoráveis para a reprodução da agricultura familiar por meio da articulação de diversas instituições de socialização da juventude rural e da sua integração nas esferas financeiras, produtivas e mercantis. Idealmente, o Pronaf pretende construir uma juventude rural capacitada para desencadear suas próprias atividades produtivas e interligada às instituições de desenvolvimento rural, aos mercados de bens e serviços e ao sistema bancário.

Dessa forma, o Pronaf Jovem representa a confluência de múltiplos investimentos sociais no sentido de reconhecimento público e de institucionalização da juventude rural, como categoria social portadora de direitos às políticas públicas no contexto contemporâneo. O Pronaf Jovem também representa um investimento social na produção de imagens que conformam um estereótipo de uma juventude rural sucessora na agricultura familiar pela conjugação de acessos aos recursos financeiros, aos meios de produção e à qualificação profissional, que possibilitam melhores inserções socioprodutivas. Em tais condições, espera-se que os jovens ingressem na vida adulta como agricultores familiares integrados aos processos de desenvolvimento rural.

A institucionalização do Pronaf Jovem situa-se em contexto estrutural e conjuntural do país muito favorável à atuação de diferentes atores sociais, inclusive representantes de movimentos sociais rurais, que tiveram oportunidades de ocupar cargos no próprio governo, ainda na primeira gestão do governo Lula. O contexto sociopolítico facilitou a ampliação dos investimentos públicos e a reorientação da política de crédito subsidiado de custeio e investimento para a agricultura familiar, com vistas ao atendimento de uma pluralidade de demandas sociais colocadas em pauta por múltiplos representantes e agentes mediadores comprometidos com as causas da agricultura familiar. Em análise retrospectiva da dinâmica do Pronaf, Schneider et al. (2004) especificam que, entre 2000 e 2004, foram instituídas diversas linhas de crédito, como Pronaf Florestal, Pronaf Alimentos, Pronaf Agroecologia, Pronaf Turismo, Pronaf Máquinas e Equipamentos, Pronaf Semiárido, Pronaf Pesca, Pronaf Mulher e Pronaf Jovem, com propósitos de contemplar a diversidade econômica, social, produtiva, regional, sexual, geracional, abrangendo, inclusive, categorias 
profissionais que nem mesmo podem ser socialmente categorizadas como agricultores familiares, a exemplo dos pescadores artesanais e, posteriormente, quilombolas e indígenas. Além disso, entre 2003 e 2010, mudanças consideráveis foram observadas quanto ao volume de recursos, número de contratos e dos valores por contratos do Pronaf, conforme estudos de Gazolla \& Schneider (2013, p. 49): "os recursos cresceram de 2,4 bilhões para 16 bilhões, o número de contratos, de 890 mil para 2 milhões por ano, e os valores médios por contrato, de $\mathrm{R} \$ 2.400,00$ para $\mathrm{R} \$ 7.478,00$ ".

Esse cenário político-institucional favorável para a agricultura familiar foi estendido à afirmação de políticas públicas para as gerações juvenis rurais, segundo Barcellos (2014a), pela agregação coletiva de forças sociais de jovens rurais e, sobretudo, de mediadores sociais vinculados às instituições e aos movimentos sociais de defesa das causas juvenis rurais, especialmente a Confederação Nacional dos Trabalhadores na Agricultura (Contag), Federação dos Trabalhadores na Agricultura Familiar (Fetraf), Via Campesina - Brasil, Movimento dos Trabalhadores Rurais Sem Terra (MST), Movimento dos Pequenos Agricultores (MPA) e Pastoral da Juventude Rural (PJR). Embora agregados a diferenciadas orientações político-ideológicas, representantes de movimentos sociais defenderam $\mathrm{O}$ crédito rural como medida necessária ao enfrentamento das nefastas consequências da "invisibilidade social" da juventude rural: migração massiva de jovens rurais, envelhecimento, desertificação e masculinização das populações rurais.

Nesse contexto, o problema da sucessão hereditária na agricultura familiar também passou a mobilizar pesquisadores, que colocaram em pauta a necessidade de criação de marcos para a inclusão social da juventude rural. Os estudos de Abramovay et al. (2001), desenvolvidos no estado de Santa Catarina, com apoio e incentivo financeiro da Organização das Nações Unidas para Agricultura e Alimentação (FAO) e do Ministério do Desenvolvimento Agrário (MDA), contribuíram para a tomada de conhecimento sobre os múltiplos constrangimentos dos processos de sucessão hereditária na agricultura familiar. No campo acadêmico, diversos pesquisadores, dentre eles destaco Carneiro (2001), Castro (2005), Stropasolas (2006) e Weisheimer (2009), somaram esforços na compreensão da problemática da sucessão hereditária na agricultura familiar e suas prováveis repercussões sobre os destinos da juventude rural e, por extensão, da própria agricultura familiar.

As providências para o necessário reconhecimento da juventude rural como categoria social portadora de direitos deveriam perpassar pela expansão de políticas públicas, garantidoras do acesso à terra, ao crédito rural e à formação técnico-profissional. Para todas as situações, as providências para a questão juvenil rural deveriam confluir para marcos da intervenção do poder público. Em ações coletivas, gestores de políticas públicas, representantes de movimentos sociais e pesquisadores empreenderam lutas sistemáticas para ampliar os montantes de crédito rural, flexibilizar as exigibilidades para a contratação, facilitar o acesso às informações e ampliar os limites da faixa etária potencialmente beneficiária.

As políticas orientadas aos jovens, assim como as instituições destinadas à socialização das gerações juvenis, também constroem determinadas condições sociais e imagens juvenis pelas tessituras de um conjunto de práticas, de concepções, de enquadramentos sociais e de expectativas futuras. O Pronaf Jovem visa, como propósito primevo, assegurar condições objetivas e subjetivas para a reprodução social do segmento categorizado como agricultura familiar. Por tal razão, uma das exigibilidades das normativas consiste na apresentação da Declaração de Aptidão ao Pronaf (DAP), que deve ser emitida por agentes vinculados às instituições credenciadas, os quais também ficam incumbidos de analisar a documentação comprobatória da qualificação profissional dos jovens rurais. Nesse sentido, a juventude rural é socialmente representada como o futuro da agricultura familiar e, especificamente, os jovens rurais representam os futuros agricultores familiares.

Se a juventude rural acena para o futuro, no presente essa categoria social também comporta enquadramentos delimitados por recortes etários. Nas edições iniciais, os potenciais beneficiários do Pronaf Jovem eram jovens rurais com idades entre 16 e 25 anos e, a partir de 2007, foi estabelecida uma faixa etária entre 16 e 29 anos. A propósito das classificações por recortes etários, Bourdieu (2011, p. 143) afirma que "as divisões entre as idades são arbitrárias" e "a fronteira entre a juventude e a velhice é um objeto de disputa 
em todas as sociedades". São, portanto, relações de poder que impõem limites e produzem ordens nos espaços em que cada agente social deve se manter, agir e pensar.

Com efeito, a definição de 16 anos como idade mínima para acesso à política do Pronaf tem relações diretas com a legislação vigente, que permite trabalho entre os 14 e 16 anos de idade, mas somente na condição de aprendiz, em conformidade com o Estatuto da Criança e do Adolescente (ECA). Considerando o princípio de formar os futuros agricultores familiares - leia-se trabalhadores familiares -, por definição legal, o Pronaf Jovem somente poderia ser concedido a partir dos 16 anos de idade. Contudo, essa delimitação etária também se constitui um critério definido arbitrariamente, conforme análise de Marin et al. (2012), pela ingerência de organismos internacionais como a ONU, Unicef e OIT e pela incorporação na legislação brasileira destinada à proteção da infância e adolescência. No outro extremo dessa delimitação, houve um aumento de quatro anos para a faixa etária de enquadramento na categoria "jovem", passando de 25 para 29 anos. Essa alteração, igualmente manipulável, foi resultado de disputas levadas a termo pelos agentes sociais imbuídos pelas causas juvenis rurais, preocupados com a ampliação dos potenciais beneficiários dessa política de crédito.

As normas do Pronaf Jovem contêm, ainda, idealizações relacionadas à produção social de uma juventude rural autônoma e empreendedora, viabilizada pelo aporte de crédito rural, com taxas de juros subsidiadas e longos prazos para quitação. O recurso financeiro criaria condições sociais para a autonomização dos jovens em relação às suas famílias pela maior facilidade de implantação das experiências produtivas, seja em atividades de interesse do próprio jovem ou em iniciativas já executadas pela família. Por ambos os caminhos, a expectativa final é garantir condições objetivas e subjetivas para que os jovens construam suas passagens para a vida adulta e afirmem-se como futuros agricultores familiares.

Por tais princípios norteadores, a juventude rural que se pretende construir é uma juventude rural dotada de recursos e capacitações para realizar investimentos produtivos e, ao mesmo tempo, interligada ao sistema bancário, às instituições de desenvolvimento rural e aos mercados de bens e serviços para viabilizar os necessários processos de sucessão na agricultura familiar. Contudo, os ideais das normativas regulamentares do Pronaf Jovem não se objetivam na realidade da maioria da juventude rural brasileira. Os dados publicados pelo MDA são reveladores do baixíssimo número de acesso ao Pronaf Jovem nas diversas regiões do Brasil. Em análise de dados publicados pela Secretaria Especial da Agricultura Familiar (SEAD), Gugel et al. (2017) afirmam que, entre 2004 e 2016, em todas as regiões do Brasil, foram firmados tão somente 2.889 contratos do Pronaf Jovem, com um montante de R\$18,6 milhões, conforme Tabela 1.

Tabela 1 - Número de Contratos celebrados pelo Pronaf Jovem no Brasil e valores em Reais, no período de 2004/2005 a 2015/2016.

\begin{tabular}{ccc} 
Ano & $\mathbf{N}^{\circ}$ Contratos & Valores (R\$) \\
$2004 / 2005$ & 18 & $129.660,00$ \\
$2005 / 2006$ & 513 & $2.973 .724,00$ \\
$2006 / 2007$ & 789 & $4.520 .957,00$ \\
$2007 / 2008$ & 805 & $5.102 .449,57$ \\
$2008 / 2009$ & 224 & $1.401 .526,26$ \\
$2009 / 2010$ & 32 & $215.196,71$ \\
$2010 / 2011$ & 56 & $483.834,77$ \\
$2011 / 2012$ & 78 & $723.869,82$ \\
$2012 / 2013$ & 25 & $316.812,88$ \\
$2015 / 2016$ & 349 & $2.729 .340,00$ \\
Total & 2.889 & $18.597 .371,01$ \\
\hline
\end{tabular}

Fonte: SEAD (2016, apud Gugel et al., 2017, p. 9). Os dados dos anos agrícolas 2013/2014 e 2014/2015 não estão disponíveis. 
O número total de contratos firmados no período em questão é muito pequeno quando confrontado com a população juvenil rural. Considerando-se que a população rural brasileira na faixa etária entre 16 e 29 anos era de 7.144.702 (Instituto Brasileiro de Geografia e Estatística, 2010), conclui-se que o Pronaf Jovem atendeu apenas 0,04\% dos jovens rurais. No entanto, é preciso considerar, conforme estudos de Wanderley (2007), Stropasolas (2006), Castro (2005, 2009), Weisheimer $(2009,2013)$ e Spanevello (2008), a diversidade social da juventude rural que, evidentemente, implica a elaboração de distintos projetos profissionais, que perpassam pelos estudos escolares, pela incorporação no mercado de trabalho e pela sucessão na agricultura familiar. Gugel et al. (2017), a partir de estudo realizado em Santa Catarina, afirmam que os jovens rurais em processos de sucessão na agricultura familiar são os principais demandantes de Pronaf Jovem, mas têm dificuldades para atender todos os seus critérios de enquadramentos, o que explica 0 pequeno número de contratos firmados. No entanto, isso não significa que os jovens rurais não tenham interesse em firmar contratos de crédito rural, considerando que:

[...] uma parcela dos jovens agricultores acessa outras linhas de crédito do Pronaf, sejam pelos limites de financiamento das mesmas (muitas vezes mais adequados às suas necessidades), pela existência de entraves burocráticos menos rígidos ou pela "posição" ocupada por estes jovens como gestores na sucessão das unidades familiares de produção. (Gugel et al., 2017, p. 9)

Gugel et al. (2017) acrescentam que os montantes de recursos financeiros do Pronaf Jovem são irrisórios quando confrontados com número de contratos e os volumes de crédito disponibilizado pelas demais linhas do Pronaf. Tomando como parâmetro o ano agrícola 2015/2016, Gugel et al. (2017, p. 7) notam que os 349 contratos no montante de $\mathrm{R} \$ 2,73$ milhões do Pronaf Jovem representam "cerca de 0,021\% dos contratos celebrados no âmbito do Pronaf no mesmo período e 0,013\% dos recursos acessados".

Em termos de planejamento, os gestores dessa política pública pretendiam facilitar o acesso aos potenciais beneficiários, ao estabelecer, em 2013, a meta de "ampliar para 150 mil o número de jovens rurais com acesso ao crédito" (Brasil, 2013, p. 13). Já no Plano Nacional de Juventude e Sucessão Rural, instituído pelo Decreto $n^{\circ} 8.736$, de 3 de maio de 2016, aqueles gestores estabeleceram como meta a concessão de crédito para 280.000 jovens rurais até 2018 (Brasil, 2016b). No entanto, dadas as recentes mudanças no cenário econômico e político brasileiro, desencadeadas pelo impeachment da presidenta Dilma Rousseff, as otimistas previsões dificilmente serão objetivadas na realidade.

Por tais razões, o Pronaf Jovem configura-se como uma política pública controversa à medida que, em termos formais, idealiza a construção da juventude rural como categoria social portadora de direitos à política de crédito, mas, na realidade social, diversos fatores dificultam os acessos aos jovens rurais e, por consequência, as tão desejadas estruturações de atividades produtivas geradoras de autonomia pessoal e sucessão na agricultura familiar.

\section{Jovem rural empreendedor: entre idealizações e realidade}

Em termos formais, o Pronaf Jovem apresenta recursos creditícios destinados a investimentos, configurando-se, portanto, como um financiamento de longo prazo e de taxas de juros abaixo da inflação ${ }^{3}$. Conforme explicitou Bianchini (2015), então Secretário da Agricultura Familiar do MDA, o Pronaf Jovem faculta aplicações dos recursos financeiros tanto para o fortalecimento da unidade de produção familiar, com propósitos de viabilizar uma sucessão hereditária a partir das unidades produtivas paternas, quanto para a elaboração de projetos independentes pelos jovens contratantes, com vistas a prepará-los

\footnotetext{
${ }^{3}$ De acordo com as diretrizes do Plano Safra 2015/2016, o Pronaf Jovem estabeleceu um limite, por beneficiário, de $\mathrm{R} \$ 16.500,00$, com prazos de dez anos e três de carência, dependendo da necessidade técnica de cada projeto financiado, e possibilidades de contratação de até três financiamentos para cada beneficiário, com taxas de juros de 2,5\% ao ano (Banco do Brasil, 2016). Em 2016, segundo dados do IBGE, a taxa de inflação oficial girou em torno $6,29 \%$.
} 
para a construção de uma nova unidade produtiva familiar. Por ambos os caminhos, ressalto, os recursos financeiros, tecnológicos e institucionais têm como propósito ampliar poderes e capacitações do jovem rural. Todo esse investimento está associado à ideia de constituir uma juventude rural autônoma e emancipada por meio da estruturação de atividades produtivas e do aprofundamento das relações mercantis.

Os propósitos seriam, ainda, contornar problema do desemprego ou da escassez de ofertas de trabalho e emprego formal, seja em agricultura, indústria, comércio e serviços, e transformar jovens rurais em empreendedores familiares, com condições de criar e gerir seus próprios negócios. Os jovens rurais contribuiriam, por consequência, na geração de trabalho e renda, na dinamização da economia local e na melhoraria das condições de vida da população rural pelo desenvolvimento do associativismo e cooperativismo e pela inserção nos diferentes mercados institucionais reservados para a agricultura familiar. Porém, a realidade pesquisada na Região Central do Rio Grande do Sul revela múltiplos limites para a objetivação de tão alvissareiro projeto para a juventude rural. Os dados obtidos por meio de questionário indicam que, entre os 191 jovens rurais respondentes do questionário, nenhum conseguiu celebrar contrato pelo Pronaf Jovem. Portanto, na região em estudo, essa política pública de crédito não atinge seus objetivos de promover mudanças na realidade da juventude rural.

Esse fato suscita a seguinte questão: quais as razões do limitado acesso do Pronaf Jovem pela juventude rural? Jovens rurais entrevistados nos municípios de Júlio de Castilhos, Toropi, Mata e Agudo revelam um importante aspecto: o desconhecimento da existência do Pronaf Jovem:

Nunca ouvi falar pelo menos. É crédito fundiário? Como assim? (Ana, 26 anos)

Não, não acessei. Nem sabia que existia esse Pronaf Jovem. (Flávia, 26 anos)

Não, nunca tirei o Pronaf Jovem. A dificuldade é a falta de conhecimento, de noção. (Laura, 21 anos)

Não, nunca peguei o Pronaf Jovem. Acho que, na minha visão, poucos conhecem. Acho que a maior dificuldade é ter conhecimento do programa. (Talita, 18 anos)

Múltiplos fatores concorrem para o desconhecimento dessa política creditícia. Um deles vincula-se aos interesses dos próprios jovens no que tange às suas perspectivas de vida futura. Os jovens rurais da Região Central do Rio Grande do Sul, majoritariamente, não tecem projetos futuros de reprodução social na agricultura familiar. Antes, os jovens constroem projetos profissionais que passam pelas vinculações nas instituições escolares e pelas inserções no mercado de trabalho assalariado. Os dados quantitativos indicam que $52,4 \%$ dos jovens continuam os estudos escolares, sendo $11 \%$ matriculados em instituições de ensino fundamental, $69 \%$ em ensino médio ou técnico, 17\% em ensino superior e 1\% em ensino de pós-graduação. Na região pesquisada, os jovens rurais percebem os estudos escolares como alternativas plausíveis para sair do meio rural e obter formação profissional para ocupações laborais mais valorizadas e mais bem remuneradas. À medida que os estudos tornam-se os principais investimentos de projetos profissionais, os jovens distanciam-se dos trabalhos familiares, não somente em decorrência da maior exigência de tempo e dedicação aos estudos, mas também pelos necessários deslocamentos espaciais para as cidades com instituições de ensino. Portanto, os jovens inseridos no sistema escolar não demonstram interesse em acessar uma política orientada à reprodução social na agricultura familiar. Weisheimer (2013), em estudo sobre projetos de jovens agricultores da região do Recôncavo Baiano, notou a existência de uma relação inversa entre a continuidade dos estudos escolares e o projeto de reprodução da condição de agricultor familiar, identificando maior recusa em ser agricultor entre os jovens rurais estudantes do que entre os jovens que não que continuavam os estudos escolares. Paulo (2014, p. 246), em pesquisa no município pernambucano de Orobó, constatou situação semelhante: “[...] ficam na atividade agrícola os jovens que não estão inseridos no sistema de ensino". 
Ademais, uma parcela dos jovens rurais pesquisados (19,4\%, segundo dados quantitativos) encontrava-se inserida no mercado de trabalho, em relações assalariadas formais ou informais. Isso não significa que esses jovens não possam continuar os estudos escolares, pois, em determinadas situações, o assalariamento é uma condição para viabilizá-los, nem significa que a vinculação em relações assalariadas seja um caminho sem retorno à agricultura, uma vez que alguns jovens procuram trabalhos assalariados como estratégia de formação de poupança na expectativa de futuros investimentos na agricultura familiar. No entanto, não se pode ignorar que o estabelecimento de relações de trabalho assalariado dificulta ou até impede a contração de crédito rural pelos jovens.

$\mathrm{Na}$ amostra quantitativa, foi constatado que $31,4 \%$ dos jovens possuem rendas próprias provenientes de atividades agrícolas. São jovens que deixaram de estudar e já colocaram em marcha projetos pessoais de permanência na agricultura familiar. Mesmo constituindo estrato numericamente considerável, os jovens rurais potencialmente sucessores na agricultura familiar não conseguiram acessar o Pronaf Jovem. Esse fato decorre não só por desconhecimento da existência dessa política pública, mas também por falta de informações quanto às possibilidades de investimentos produtivos dos recursos contraídos no Pronaf Jovem. Os jovens não se sentem bastante seguros para contrair crédito rural nem realizar investimentos produtivos sem a devida apropriação de conhecimentos, tecnologias e alternativas de comercialização existentes no município e na região. O depoimento de uma jovem rural de Tupanciretã elucida:

Já ouvi falar no Pronaf Jovem, mas assim não acessei. O principal problema é saber que existe o Pronaf Jovem. Mas, saber onde tu vai investir, principalmente. O que é que pode fazer e no que investir. O jovem tem que saber que ele pode até acessar. Mas que vai ter que investir em alguma coisa que dê lucratividade. (Viviane, 24 anos, Tupanciretã).

Pelo exposto, os jovens rurais precisariam, além de informações para contratar crédito, redes de apoios familiares e institucionais para implantação de suas atividades produtivas, com perspectivas de geração de rendimentos compensatórios. É preciso considerar que implantar ou aperfeiçoar uma atividade produtiva implica o domínio de conhecimentos técnicos, administrativos e mercadológicos, bem como o compromisso, firmado em contrato bancário, de ressarcir o crédito rural contraído. Essas condicionantes têm sérias implicações sobre a vida dos jovens rurais pela imposição de responsabilidades na condução das atividades produtivas agrícolas, que podem resultar em perdas econômicas tanto pela desigualdade entre os custos de produção e os valores pagos aos produtos agrícolas quanto pelas oscilações dos preços de mercado. Existem, ainda, conforme narrativas de jovens rurais ${ }^{4}$, riscos provocados por acidentes da natureza, que, dadas as condições naturais de realização da produção agrícola, na maioria das vezes aleatórias e não controláveis, podem acarretar perdas de produção agrícola e aumentar a instabilidade da renda familiar.

Em cenários de dívidas, os jovens rurais teriam seus processos de autonomização muito comprometidos pelas nefastas repercussões sobre a sua vida futura. O temor e cautela implicados tanto na estruturação de atividade produtiva quanto nas transações bancárias e mercantis são perfeitamente compreensíveis nessa população juvenil rural, dotada de poucos recursos socioeconômicos, mas desejosa de construir caminhos minimamente seguros de emancipação pessoal. Os jovens rurais pesquisados, conforme explicitado nas seções subsequentes, vivenciam diversos constrangimentos para implantação de suas atividades produtivas, de comprovação de atividades de formação profissional e de adequação às normas bancárias estabelecidas pelas diretrizes do Pronaf Jovem.

\footnotetext{
${ }^{4}$ Os jovens rurais relataram problemas de chuvas torrenciais, estiagens, ventanias e chuvas de granizo, que causam perdas significativas, sobretudo, na cultura do tabaco, importante produto mercantil das famílias de agricultores da Região.
} 
O ideal da pluriatividade e sua difícil objetivação pelos jovens rurais

O Pronaf Jovem, pelas normativas, prevê que os montantes de recursos financeiros podem ser aplicados no desenvolvimento de atividades agrícolas e não agrícolas vinculadas à agricultura familiar. De maneira mais detalhada, o crédito pode ser aplicado na criação de animais, aquisição de máquinas e equipamentos agrícolas, recuperação de solos, implantação de pomares, formação e recuperação de pastagens, construção, reforma ou ampliação de benfeitorias e instalações rurais, bem como o desenvolvimento de atividades na agroindústria, serviços ou artesanato familiares (Banco do Brasil, 2016). Dessa forma, o Pronaf Jovem disponibiliza recursos financeiros para um leque diversificado de alternativas, a fim de que os jovens iniciem seus projetos produtivos, desenvolvendo seu próprio negócio em agricultura, agroindústria, turismo rural ou artesanato, na expectativa de gerar renda própria e construir a autonomia pessoal. Ao facultar apoios para múltiplos investimentos, o Pronaf idealiza a diversificação produtiva, com vistas a potencializar diferenciadas aptidões regionais de produção, aliada aos valores da preservação dos recursos naturais. Idealiza, ainda, o desenvolvimento de diversas qualificações laborais pela concessão de recursos que podem ser destinados às atividades de turismo rural e artesanato, que implicariam a valorização do meio ambiente e dos saberes e fazeres locais.

Vale notar que o Pronaf Jovem incorporou noções da pluriatividade da agricultura familiar, tema que teve grande repercussão no meio acadêmico a partir da década de 1990. A noção de pluriatividade, segundo Schneider (2003a, 2003b), remete aos processos sociais em que os membros de uma família rural dedicam-se a uma diversidade de atividades econômicas, com a combinação de atividades agrícolas e não agrícolas, praticadas dentro ou fora da propriedade familiar. A noção de pluriatividade passou a ser usada como uma forma adequada para a análise da multiplicidade de formas de inserção no trabalho e de geração de renda das unidades agrícolas familiares. Portanto, nos estudos da pluriatividade, a família rural torna-se a unidade privilegiada para a observação e análise sociológica, na busca de compreensão dos fenômenos sociais que levam alguns de seus membros a estabelecer conjugações de atividades agrícolas e atividades não agrícolas. Isso também implica reconhecer que as famílias de agricultores englobam uma diversidade de situações socioprodutivas e laborais e de estratégias de reprodução social.

As pesquisas sobre a pluriatividade tiveram importante contribuição na elaboração ou redefinição de políticas públicas orientadas para a agricultura familiar. Segundo Escher et al. (2014), o Pronaf incorporou, em suas linhas de financiamento, a conjugação de atividades agrícolas com as atividades não agrícolas, e seus respectivos rendimentos, como critérios de enquadramento do seu público-alvo, ampliando, ao menos em tese, a abrangência dos potenciais beneficiários desse crédito rural. Vale ressaltar que a noção de pluriatividade também foi incorporada nas diretrizes do Pronaf Jovem, contribuindo na idealização de uma juventude rural dotada de capacitações para desenvolver múltiplas atividades produtivas.

Com propósito de tecer um panorama produtivo das famílias, dentre os 191 jovens pesquisados, 89,5\% informaram que têm rendas provenientes de atividades agrícolas; $56,5 \%$, de atividades pecuárias; 31,9\%, de aposentadorias; $28,2 \%$, de trabalhos assalariados formais ou informais; $12 \%$, de programas de transferência de renda; 5,8\%, de agroindústria familiar; 2,1\%, de microempresariados; e 1\%, da silvicultura extrativismo vegetal. Esses dados revelam que, de certa forma, as famílias dos jovens rurais combinam uma ou mais atividades produtivas para a composição da renda familiar. No entanto, são consideráveis os percentuais de rendas relacionadas ao assalariamento e benefícios sociais entre as famílias dos jovens rurais. Antes de potencialidades, tais formas de composição de renda são indicadoras de constrangimentos que as famílias dos jovens enfrentam para colocar em prática o trabalho familiar, sejam decorrentes das limitações da unidade produtiva em absorver todo o contingente da mão de obra familiar ou das dificuldades para obtenção de rendas agrícolas satisfatórias. Indicam, por fim, constrangimentos para os processos de reprodução social de parcelas consideráveis de famílias de agricultores pesquisados.

No que tange à produção agropecuária, ainda com base nos dados quantitativos, a principal atividade é o tabaco para 30,4\% das famílias dos jovens, soja para 13,6\%, milho para $12,6 \%$, leite para $11,5 \%$, gado de corte para $10,5 \%$, arroz para $6,3 \%$, frutas para $5,2 \%$, 
feijão para 2,6\%, mandioca para 2,1\%, suínos e ovinos para $1,5 \%$, enquanto 3,7\% não responderam. Apenas $2,1 \%$ dos jovens informaram que suas famílias comercializam suas produções nas feiras locais e 3,1\% estão inseridas nos mercados institucionais por meio do Programa de Aquisição de Alimentos (PAA) ou do Programa Nacional de Alimentação Escolar (PNAE). As principais produções agropecuárias - tabaco, soja, milho, arroz, bovinocultura de leite e de corte - são viabilizadas nos processos de integração agroindustrial ${ }^{5}$. Evidentemente, cada uma dessas atividades produtivas reserva especificidades nas relações técnico-produtivas, mercantis e contratuais, tecidas com os setores financeiros, industriais, comerciais e de serviços.

Contudo, para compreender mais a pluriatividade nos municípios estudados, acredito oportuno especificar a análise em torno do tabaco por duas razões fundamentais: o tabaco é o principal produto mercantil das famílias de jovens pesquisados; e, entre os jovens pesquisados, o debate da questão da pluriatividade está relacionado ao desenvolvimento de sistemas agrícolas diversificados em substituição ao tabaco. Dessa forma, diversificar as atividades produtivas tornou-se tema de debate corrente entre agentes de desenvolvimento rural, agricultores e jovens rurais em virtude do Programa Nacional de Diversificação Produtiva em Áreas com Cultivo do Tabaco, instituído pelo MDA a partir da ratificação da Convenção Quadro para o Controle do Tabaco em 2005 (Brasil, 2006).

Alguns apontam vantagens na integração agroindustrial do tabaco relacionadas à viabilização da produção familiar e garantia de mercado, conforme depoimento de Mário (26 anos, Mata): “Acredito que nosso lugar está numa monocultura do pequeno. Tu planta fumo, tu tem lucro. Tu planta outra coisa, nem mercado tu consegue". Outros ressaltam a importância da assistência técnica oportunizada no sistema de integração agroindustrial do tabaco. Embora existam referências de atuação técnica limitada à tomada das assinaturas dos contratos agrários, jovens entrevistados revelam ações das equipes técnicas orientadas para dirimir as dúvidas técnicas, contratuais e comerciais dos agricultores integrados: “Nós não temos assistência técnica da Emater, só da firma [agroindústria de tabaco] mesmo. O instrutor que vai lá, conversa, olha como que tá a plantação, sempre dá aquele auxílio. Trazem informações de comercialização também" (Talita, 18 anos, Agudo).

Os jovens rurais, em seus depoimentos orais, também revelam que os principais conflitos originam-se das trocas desiguais entre os preços dos fatores de produção máquinas, insumos agrícolas, estufas e serviços - e os preços estabelecidos para a folha de tabaco, transações essas normalmente desfavoráveis aos agricultores familiares. Tais mecanismos, por fim, reduzem as margens de ganho das famílias e dificultam a criação de poupanças e investimentos em projetos familiares:

Como eu disse, aqui, tu trabalha, trabalha, trabalha... Resumindo, às vezes, dá até aquele desânimo na gente porque tu pensa: "trabalhei, tá, e agora? Pra isso, tão pouco?" Podia pagar um pouco mais, né? A gente planta fumo, vai lá na firma, briga pelo preço, passa aquele fumo na esteira. A gente tá brigando com os compradores lá dentro, daí eles param a esteira. Não adianta brigar: ou tu traz o fumo embora de volta e deixa no galpão ou tu tem que se contentar. Só que eu disse: enquanto eles tão lá trabalhando bonitinho, como é que foi que aquele produto chegou lá? Será que eles, todo mundo que tá lá, realmente sabe como é que aquele fardo de fumo chegou lá? Não sabe da onde que sai, como sai. Então, eu digo que a valorização do produto já seria um grande feito pro jovem ficar aqui no meio rural. (Mariana, 27 anos, Júlio de Castilhos).

Além da remuneração insatisfatória do produto do trabalho familiar, jovens rurais entrevistados agregam problemas relacionados à penosidade, intensidade do ritmo de trabalho e, especialmente, à insalubridade decorrente dos riscos de intoxicações por agrotóxicos. As lidas com o tabaco são representadas, conforme expressão de jovem rural, "um trabalho que judia muito da pessoa". Isso representa trabalhos extenuantes, desgastantes e perigosos pelas prováveis repercussões nefastas sobre a saúde física e

${ }^{5}$ Entre os agricultores dessa Região, a produção de milho é destinada à alimentação da família e, sobretudo, dos animais. Merece, portanto, a ressalva de que o milho nem sempre tem prioridade mercantil. 
mental. Por tais razões, os jovens rurais demonstram, mais do que os adultos, disposições para desenvolver novas atividades produtivas em substituição ao cultivo do tabaco, conforme relato:

A minha ideia é eu parar de plantar fumo e partir para produzir alimentos. Parar de produzir só o fumo e depender só de uma cultura. Tenho uma lavoura de pessegueiro plantada que vai começar a produzir no próximo ano, e tenho uma lavoura de tomate e alface, a princípio na estufa. E mais adiante quem sabe aumentar e diversificar. (Mário, 26 anos, Mata).

Agentes vinculados às diversas instituições de desenvolvimento rural passaram a investir na discussão e experimentação de novas alternativas produtivas e mercantis, que facilmente reverberam entre os jovens rurais. As predisposições para o desenvolvimento de novas atividades produtivas vinculam-se com as ideais de romper com a dependência da monocultura nas unidades de produção familiar. Não obstante, os jovens entrevistados confrontam suas aspirações com múltiplos problemas para operacionalizar a substituição dessa cultura tradicional na região por novas alternativas produtivas de interesses mercantis. Uma barreira, na visão de jovem entrevistado, refere-se à construção social de mercados para as novas atividades produtivas:

Outra política pública seria o incentivo a novas culturas, seria importante também oferecer o mercado, abrir indústrias que deem renda e outras oportunidades ao jovem. Hoje, a gente vê, que moranguinho, peixe, todos os produtos de hortaliças dão dinheiro, mas o mercado para vender é ruim. É difícil de chegar até esses lugares de vendas. (Luciano, 19 anos, Agudo).

É notável que os debates em torno da produção de tabaco criaram, socialmente, consensos de que a diversificação produtiva apresenta-se como caminho para substituição das produções integradas com grandes agroindústrias de processamento, mas que se confronta com a necessidade urgente de construção de novos canais de comercialização. Sem garantias de agregações em novos mercados, evidentemente, todo o investimento e o trabalho realizados tornar-se-iam demasiadamente arriscados e comprometedores da organização socioeconômica do estabelecimento familiar.

A agroindústria familiar, pela agregação de valor aos produtos agropecuários, também tem sido percebida como estratégia para ampliar a autonomia do trabalho e a renda das famílias de agricultores, conforme depoimento oral: “Queria colocar uma agroindústria, alguma coisa assim, para desenvolver mais alimentos para o consumo das escolas ou do meio rural. Para ajudar mais nas contas da casa" (Flávia, 26 anos, Toropi). No entanto, o desejado projeto de agroindustrialização confronta-se com as determinações da legislação sanitária dos produtos de origem animal e vegetal. A atuação de agentes da vigilância sanitária, pautada na apreensão de produtos e multa de agricultores não legalizados, gera não somente indignações entre os jovens rurais entrevistados, mas também temores e desestímulos quanto às reais possibilidades de investimentos em agroindústrias familiares, conforme depoimento de uma jovem de Agudo:

Aqui seria bom trazer novas alternativas de produção. O pessoal é bastante dependente do fumo. Mas eu vejo também que muitos que agricultores produzem pra vender no comércio local. Só que agora com fiscalização, no mês passado teve aquela fiscalização aqui em Agudo. Não sei se tu chegou a ver... Muitos: "ah, não vou ficar, o que eu vou produzir eu não vou poder vender!" Acho que é uma coisa que também poderia ser procurado alternativas para esses produtores, pra conseguirem vender aqui no comércio local. Eles recolhem os produtos e não deixam vender, isso é uma coisa que desanima. "Ah, vou produzir e não vou poder vender! (Talita, 18 anos).

Mesmo as aspiradas inserções agroindustriais da agricultura familiar são de difíceis objetivações, derivadas não somente das restrições legais ou mercantis, mas pelo acesso aos recursos financeiros para implantar empreendimentos dessa envergadura. Jovens rurais entrevistados se apropriaram dos debates relacionados à diversificação produtiva que emerge em torno do cultivo de tabaco e aspiram integrar-se aos seus propósitos, mas 
entendem que são necessários recursos financeiros e preços satisfatórios aos produtos, além de redes e espaços de mercados mais justos. Reconhecem, ainda, a necessidade de serviços de assistência técnica e extensão rural, os quais também não conseguem acessar.

Pronaf Jovem: entre as pretensões e as possíveis interconexões institucionais

Outra idealização do Pronaf Jovem refere-se à a formação de jovens rurais qualificados profissionalmente, ao vincular o financiamento rural com a comprovação de cursos proporcionados por instituições de ensino formal ou informal. A intenção dos gestores dessa política pública seria formar uma juventude rural integrada às instituições de desenvolvimento rural pelas obrigatoriedades de interconexões entre as agências bancárias e instituições encarregadas pela transmissão de conhecimentos técnico-produtivos, mercadológicos e sociais. As instituições educativas são reconhecidas como o lugar que transmite tecnologias e conhecimentos, concede certificados e, ao mesmo tempo, cultiva aspirações nos jovens rurais, ou seja, o lugar privilegiado à continuidade de socialização da juventude rural sucessora na agricultura familiar.

Ao longo das edições anuais, foram flexibilizados tanto os critérios referentes às formas de qualificação profissional quanto o leque de instituições autorizadas a ofertar cursos de formação à juventude rural. Referente à qualificação, conforme orientações do Plano Safra 2015/2016, o Pronaf Jovem pode ser concedido aos jovens rurais que comprovem um ou mais critérios de enquadramento: a) ter concluído ou estar em fase de conclusão de curso em centros familiares rurais de formação por alternância ou em escolas técnicas agrícolas de nível médio; b) estar matriculado, há mais de um ano, em curso de ciências agrárias ou veterinária em instituição de ensino superior; c) dispor de orientação de instituições de assistência técnica e extensão rural; d) participar de cursos de formação do Programa Nacional de Acesso ao Ensino Técnico e Emprego (Pronatec) ou do Programa Nacional de Educação no Campo (Pronacampo) (Banco do Brasil, 2015).

Esses critérios apoiam-se na crença de que, mediante cursos de qualificação profissional, os jovens rurais possam implantar e gerir um projeto produtivo bem-sucedido a partir da incorporação de conhecimentos, tecnologias e processos modernos e sustentáveis nos aspectos econômico, ambiental e social. A expectativa também é que os jovens rurais possam atuar como agentes sociais multiplicadores de conhecimentos e de experiências inovadoras no campo, além de isso configurar evidências reais das possibilidades de trabalho, de vida e, sobretudo, de crescimento econômico no meio rural. Sob esse prisma, o Pronaf Jovem idealiza construir uma juventude rural integrada às instituições educativas, com vistas não somente a operar mudanças nas bases produtivas, mas também gerar referências para outros jovens rurais sucessores na agricultura familiar.

Nesse sentido, o Pronaf Jovem também se constitui um instrumento de intervenção do poder público nos domínios das relações familiares, na medida em que pretende capacitar os jovens rurais para que criem condições para iniciar ou aperfeiçoar atividades produtivas familiares, independentemente das limitações ou conflitos vivenciados no seio familiar. Pesquisadores dedicados aos estudos da juventude rural, dos quais destaco Stropasolas (2006), Castro (2009) e Weisheimer (2009), evidenciaram que as relações familiares hierarquizadas, fundamentadas no patriarcalismo, tendem a concentrar os poderes e recursos em torno do homem, pai e chefe de família, que acabam por comprometer a autonomia dos jovens rurais e, mais acentuadamente, das jovens rurais, com sérias repercussões sobre os processos de gestão da unidade produtiva familiar e de sucessão hereditária. Como assevera Castro (2009), a condição social de jovem rural sempre implica posições de subalternidade, mas a condição de jovem rural e mulher representa maior subordinação nas estruturas hierárquicas familiares e sociais.

Ao alocar recursos financeiros e tecer um conjunto de relações institucionais, o Pronaf Jovem pretende colaborar para a transferência de poderes aos jovens rurais e, de certa forma, reduzir a influência da hierarquia e o domínio adulto na família. Em tese, as novas relações institucionais e econômicas, possibilitadas pelas tessituras do financiamento, conferem aos jovens rurais contratantes recursos para, enfim, corroborarem em seus processos de autonomização diante dos membros adultos da família de pertença. 
Os recursos financeiros alocados aos jovens rurais são, também, poderes que engendram maior autonomia pessoal para investir produtivamente.

A partir das interconexões institucionais, idealmente, o Pronaf Jovem pretende configurar-se como um instrumento de interligação da juventude rural ao Estado e às redes de agentes e organizações sociais, públicas e privadas, imbuídas pelos interesses da produção agrícola e do desenvolvimento rural. Nessas redes sociais, os jovens encontrariam suportes para romper as dificuldades inerentes à implantação de suas atividades produtivas e aos seus processos emancipatórios e, por consequência, construiriam caminhos mais sólidos para firmarem-se como futuros agricultores familiares qualificados. Todavia, com base no estudo da realidade de municípios da Região Central do Rio Grande do Sul, é notável a fragilidade das redes institucionais de apoios e solidariedades em prol da apropriação de saber, tecnologias e processos, especialmente para os jovens rurais que pretendem a sucessão hereditária na agricultura familiar. As instituições públicas, as organizações dos agricultores familiares e as associações dos próprios jovens rurais são inoperantes ou têm uma atuação isolada ou descontínua e, por consequência, não conseguem tocar nas questões fundamentais da juventude rural.

A falta de prioridade para as políticas afirmativas para a juventude rural é extensiva às instituições públicas encarregadas pelos serviços de assistência técnica e extensão rural. Aproximadamente, $77 \%$ dos jovens respondentes do questionário informaram que suas famílias recebem os serviços da Emater, mas não regularmente. Mormente, esses serviços são recebidos esporadicamente e mediante solicitação da família de agricultores, conforme depoimento oral:

A princípio, aqui não recebe assistência técnica. Olha, a assistência técnica avaliando hoje é bem precária. Tá bem precária mesmo! É bem difícil ter assistência, tem que vir na cidade e pedir. A gente tem que correr atrás. A gente vai lá e pede informação, pede na Emater. Enfim, quem tem anseio vai atrás. (Viviane, 24 nos, Tupanciretã).

Além de descontínuos ou esporádicos, os serviços desenvolvidos pelos agentes de extensão rural são destinados aos homens e às mulheres, ou seja, aos adultos das famílias de agricultores e não aos jovens rurais. Os cursos formação do Pronatec e Pronacampo, que poderiam comprovar qualificação para efeitos do Pronaf Jovem, nunca foram acessados pelos jovens rurais. Portanto, na região estudada, tais programas em nada modificam a vida dos jovens rurais, uma vez que existem apenas no papel.

A propósito das possibilidades de comprovação de qualificação por meio de escolas técnicas agrícolas ou cursos superiores nas ciências agrárias, igualmente previstos nas normas do Pronaf Jovem, não fazem muito sentido para os jovens pesquisados na Região Central do Rio Grande do Sul. Embora sejam grandes facilidades para matricular-se e diplomar-se em cursos técnicos em agropecuária ou em cursos superiores das ciências agrárias, os jovens que se encontram nessas condições "não querem mais voltar para o campo", conforme afirmações de jovens entrevistados. Na realidade pesquisada, todos os investimentos em estudo são percebidos, tanto pelo jovem rural quanto pela sua família, como meio de inserção no mercado de trabalho assalariado, preferencialmente fora da agricultura familiar, enquanto os diplomas obtidos são percebidos como passaportes para emancipação pessoal e ascensão social. Por tais motivos, afora situações particulares, o crédito rural não ganha muitos sentidos aos jovens estudantes ou diplomados, uma vez que as migrações e as ocupações urbanas são delineadas em seus horizontes.

Porém, na região em estudo, para os jovens rurais que pretendem permanecer na agricultura familiar, não se constituiu uma rede de instituições comprometidas com a qualificação profissional da juventude rural, que ofereçam serviços de assistência técnica e extensão rural ou cursos de formação do Pronatec e do Pronacampo. Por consequência, esses jovens rurais, que deveriam ser os beneficiários preferenciais do Pronaf Jovem, não conseguem atender às exigências de comprovação de formação profissional. Esse problema era generalizado em todo o país, considerando que, em 2007, Fabiano Kempfer (2007, p. 82), então coordenador de políticas para a juventude rural do MDA, reconhecia: 
conseguimos, de certa forma, estragar a proposta do Pronaf Jovem no momento em que estabelecemos um critério técnico a mais, que foram as 100 horas de capacitação. O governo nunca ofereceu programas de formação e capacitação para a juventude rural e agora exige uma certificação de 100 horas dos jovens rurais para que eles acessem o programa de crédito!

Embora existam críticas das incongruências do poder público, desde então as mudanças encaminharam-se no sentido de ampliar o leque de possibilidades de comprovação dos cursos de qualificação, mas sem suprimir a exigência de comprovação de cursos. Por tal razão, uma coordenadora da Comissão Nacional da Contag denunciou que as medidas de flexibilização, ao facultar certificados de cursos de qualificação pelas escolas agrotécnicas ou escolas-famílias, não tinham repercussões na juventude rural nordestina pelo fato de não existirem essas modalidades de ensino nos estados da Região Nordeste (Anastácio, 2007). Costa \& Ralisch (2013), em pesquisa realizada com jovens rurais de assentamento do estado do Paraná, também notaram a existência de entraves no acesso ao Pronaf Jovem exatamente pela dificuldade de comprovar a realização de cursos de formação técnica agropecuária, embora eles tivessem propostas de melhorias das atividades de bovinocultura de leite já desenvolvidas nas propriedades.

Em suma, por meio das orientações burocráticas do Pronaf Jovem, os mediadores políticos idealizam amplas redes de apoios institucionais para qualificar os jovens rurais nos aspectos técnicos e mercadológicos necessários à implantação de suas atividades produtivas. Porém, no plano dos municípios de estudo, não existem organizações sociais articuladas para o desenvolvimento de ações junto ao segmento de jovens rurais que estabelece projetos profissionais de permanência na agricultura familiar. Como não conseguem comprovantes de qualificação, fornecidos por instituições credenciadas, esses jovens rurais sucessores na agricultura familiar ficam impossibilitados de celebrar contratos do Pronaf Jovem.

Sistema bancário: possíveis vinculações e exclusões sociais

Os constrangimentos vividos por jovens rurais ganham outras dimensões quando a análise recai nas relações estabelecidas com o sistema bancário. Para efeitos normativos, os agentes e gestores políticos comprometidos com as causas juvenis rurais idealizaram a disponibilização de uma ampla rede bancária apta a firmar contratos. De acordo com informações do MDA (Brasil, 2013), o rol de opções de bancos autorizados a operar o Pronaf Jovem estendeu-se, além dos bancos oficiais federais (Banco do Brasil, Basa e BNB), às redes de bancos estaduais e de cooperativas de crédito, que operam com recursos captados do BNDES (Bansicredi, Bancoob, Cresol Central, Cresol Baser, Banrisul, BRDE, Bandes, BRB e bancos privados). Outras alterações nas diretrizes do Pronaf Jovem, segundo agentes sociais encarregados pela gestão de políticas para a agricultura familiar, encaminharam-se no sentido da ampliação dos montantes de recursos financeiros, da desburocratização dos mecanismos de acesso ao crédito rural e do aumento das facilidades para ressarcimentos dos empréstimos. Todas essas medidas visaram facilitar o acesso da juventude rural ao crédito e aumentar o número de contratos firmados (Brasil, 2014).

Em termos práticos, as iniciativas de contrair financiamento esbarram nas determinações burocráticas do sistema bancário. Um problema, conforme depoimentos de jovens rurais, referese à vinculação da DAP do jovem à DAP do principal chefe da unidade produtiva. Agrega-se, ainda, o endividamento da família, que implica o denominado "CPF sujo", decorrente, de maneira geral, de empréstimos bancários não quitados. Pelas dívidas em aberto e pelo cruzamento de CPFs de pais e filhos, os jovens rurais ficam impedidos em contrair o Pronaf Jovem. Isso tudo causa sérias implicações na organização dos papéis comprobatórios, conforme depoimento:

Não, não consegui acessar. Na época que eu fui pra fazer foi em 2012. Nenhum jovem aqui de Júlio de Castilhos tinha conseguido acessar. Não sei agora, 3 anos pra cá, pode ser que alguém tenha conseguido, mas que eu saiba não. Burocracia, né? É complicado, tu tem que correr atrás de papéis, fazer declaração, correr atrás de notas. A questão da burocracia impede muito. Chega na hora muitos desistem. Eu fui um que desistiu. (Ricardo, 24 anos, Júlio de Castilhos). 
Além de exigências burocráticas, os jovens enfrentam problemas nas negociações com os funcionários das agências bancárias autorizadas, que tendem a dificultar ou negar a contratação do Pronaf Jovem. Barcellos (2014b, p. 55), em debates de avaliação de políticas públicas para a juventude rural, frisou que "muitas vezes, o funcionário do banco está desinformado em relação às políticas públicas de juventude". Além da "desinformação" ou falta de informações precisas, podem ser levantadas como hipóteses que as práticas de agentes bancários revelam outras facetas importantes das limitações na execução da política pública: preconceitos contra jovens ou seu não reconhecimento como sujeitos de direitos. Outra possibilidade seria os custos administrativos não compensatórios dos contratos do Pronaf Jovem, o que significaria que os jovens rurais não são clientes atraentes aos negócios dos bancos. Embora tais suposições necessitem de aprofundamentos, o fato concreto é que práticas sociais de agentes bancários resultam, para os jovens rurais, na exclusão da possibilidade de serem beneficiários de uma política legalmente garantida.

Ainda nesse debate, jovens entrevistados revelam outro aspecto dessa problemática: a falta de confiança de funcionários de bancos na capacidade de os jovens rurais pagarem o crédito contraído. Desse modo, os jovens rurais representariam um público de risco para os bancos:

Eu acho que a questão do crédito é importante. Eu acho que é o banco que não acredita no jovem ainda, tem medo. Quando eu fui financiar eles não quiseram liberar pra mim por desconfiar que eu não ia pagar. Eu acho que tem que ter mais confiança, que já tem uma área de crédito pro jovem. (Ricardo, 24 anos, Júlio de Castilhos).

Na percepção do entrevistado, os funcionários de bancos não depositam confiança e credibilidade nos jovens demandantes do Pronaf Jovem. Assim, os jovens são percebidos como maus pagadores ou incapazes de honrar contratos, mesmo sem a existência de provas factuais. Considerando que os jovens não têm conseguido firmar contratos na linha Pronaf Jovem, Maciel Cover (2014, p. 63), representante de movimentos sociais, em avaliação de políticas juvenis rurais, também criticou a percepção generalizada de que "os bancos pensam que a juventude é um público de risco para emprestar dinheiro".

No ano de 2007, o senhor Fabiano Kempfer (2007, p. 116), na condição de coordenador de políticas para a juventude rural do MDA, relatava: "Temos, hoje, 18 milhões de reais disponíveis no sistema bancário para o acesso do Pronaf Jovem e não conseguimos gastar porque não temos demanda de acesso ao Programa". Desde então, ninguém conseguiu demover contraditória situação, daí que o dinheiro continuou disponível nos bancos e muitos jovens rurais desejavam apoios financeiros para colocarem em marcha seus projetos de desenvolvimento pessoal, familiar e social. Em torno do Pronaf Jovem, de um lado, socialmente, reproduzem-se idealizações de uma juventude adequada ao desenvolvimento rural sustentável e, de outro lado, jovens rurais continuam seus processos de autonomização pessoal, que não se realizam pelas vias dos recursos do crédito rural, pois estes permanecem retidos nos cofres do sistema bancário.

Porém, vale destacar que jovens rurais conseguem financiamentos agrícolas em outras linhas do Pronaf. Gugel et al. (2017, p. 10-11), com base em dados do SEAD e do Banco Central do ano agrícola de 2016 , afirmaram que "10,4\% dos contratos e $11,8 \%$ dos valores disponibilizados pelo Pronaf em todo o país destinaram-se a beneficiários com até 29 anos [...]. Em termos absolutos, isso representa mais de 171,6 mil contratos e $\mathrm{R} \$ 2,65$ bilhões". Os autores acrescentam que, embora esses números sejam significativos, ao contrapor a uma população rural de, aproximadamente, 8 milhões de pessoas com idades entre 16 e 29 anos, conforme apurado no Censo do IBGE de 2010, a conclusão é de que somente $2,1 \%$ dos jovens rurais conseguiram acessar o Pronaf, caso, hipoteticamente, tivessem celebrado apenas um contrato. Nos municípios gaúchos pesquisados, do total de 191 jovens rurais, seis afirmaram ter acessado outras linhas do Pronaf. Já nas entrevistas, jovens rurais também relatam mais facilidades para celebração de contratos em outras linhas do Pronaf do que propriamente no Pronaf Jovem: 
Eu não consegui o Pronaf Jovem, só o Pronaf A. Tem muita burocracia no Pronaf Jovem, porque a maioria tenta e não consegue. Não conheço ninguém da região que acessou o Pronaf Jovem. (Mário, 26 anos, Mata).

Pronaf normal sim, mas Pronaf Jovem não. Acho que muitos nem sabem que ele [Pronaf Jovem] existe. Não conheço ninguém mesmo que acessou. Eu fiquei sabendo do Pronaf Jovem, mas não acessei. Fiquei sabendo depois que eu tinha feito os outros [linhas de Pronaf]. Já tinha comprado o que eu queria. Aí, não me interessava fazer mais um. O Pronaf normal foi bem tranquilo pra mim fazer. (Davi, 29 anos, Agudo).

Vale registrar que tanto os dois jovens interlocutores quanto os cinco jovens da amostragem quantitativa são casados e com mais de 25 anos de idade. É possível aventar que o estado civil e a faixa etária tendendo para a vida adulta implicam facilidades no sentido de obterem a própria DAP, isentarem a comprovação dos cursos de qualificação e conquistarem a confiança e credibilidade junto aos funcionários dos bancos. Com o casamento, provavelmente, esses jovens rurais ascendam à condição de adulto perante a sociedade e, por consequência, conquistem posições que conferem facilidades na obtenção dos papéis exigidos e credibilidades para as transações bancárias.

\section{Considerações finais}

O Pronaf Jovem, como política pública, idealiza a criação condições favoráveis para a permanência do jovem no campo, para viabilizar a sucessão hereditária na agricultura familiar e enfrentar o problema do êxodo rural, que produz esvaziamento, envelhecimento e masculinização das populações rurais. Idealiza, enfim, a construção social de jovens rurais autônomos e qualificados para o enfrentamento dos desafios da agricultura familiar e do desenvolvimento rural. Essa juventude rural, idealmente produtiva, autônoma e integrada socialmente, representa uma metáfora de uma agricultura familiar desejável ao Brasil.

Porém, os ideais do Pronaf Jovem não se concretizam na realidade da juventude rural de municípios da Região Central do Rio Grande do Sul. Nas experiências dos jovens rurais, predominantes são o desconhecimento, a desinformação, a falta de instituições para qualificação de jovens agricultores, as exigências burocráticas de difícil atendimento, que restringem a celebração de contratos de crédito. Diante de tantas limitações, essa política não passa de uma boa intenção do poder público em construir jovens rurais emancipados e sucessores na agricultura familiar: uma ideia muito bem delineada no papel, mas de difícil objetivação na realidade dos jovens rurais.

Ao largo do Pronaf Jovem, os jovens rurais, por meio de apoios familiares e agregações a outras instituições de socialização, políticas públicas e oportunidades laborais, tecem seus processos de emancipação pessoal em estratégias diversas, consubstanciadas pelas vinculações em instituições escolares, no mercado de trabalho assalariado e na sucessão hereditária na agricultura familiar. Os distintos delineamentos de futuras inserções laborais são indicadores das diferenciadas formas de viver e perceber a juventude rural. Indicam, ainda, as diferenciadas formas de construções sociais da juventude e estratégias para ingressar para a vida adulta.

Assim, jovens rurais, em grupo maioritário, investem na continuidade dos estudos escolares, fundamentados na crença de que são caminhos privilegiados de qualificações necessárias para conquistas de ocupações laborais fora da agricultura, que, por fim, garantirá a ascensão social. Para outros, no entanto, a emancipação pessoal e financeira passa pelas inserções laborais, em relações de trabalho formal ou informal. Uma parcela de jovens rurais constrói seus processos de autonomização pessoal pelo trabalho na agricultura, mediante a integração em cadeias produtivas de complexos agroindustriais que operam na região, que Ihes garantem recursos financeiros e tecnológicos, assistência técnica e mercado para a produção agrícola. Em tais relações, os jovens conseguem objetivar a produção e comercialização da produção agrícola, não obstante, em relações sociais marcadas pela subordinação e expropriação. É exatamente esse segmento da juventude que o Pronaf Jovem deveria beneficiar, conferindo-lhes recursos financeiros e 
qualificações para construir seus processos de autonomização pessoal e de sucessão na agricultura familiar.

\section{Referências}

Abramovay, R., Silvestro, M. L., Mello, M. A., Dorigon, C., \& Baldissera, I. T. (2001). Os impasses sociais na sucessão hereditária na agricultura familiar. Florianópolis: Epagri; Brasília: MDA.

Anastácio, E. (2007). Políticas públicas, direitos e participação. In E. G. Castro \& M. J. Carneiro (Orgs.), Juventude rural em perspectiva (pp. 90-94). Rio de Janeiro: Mauad X.

Banco do Brasil. (2015). Plano Safra 2015/2016. Brasília: Banco do Brasil.

Banco do Brasil. (2016). Pronaf Jovem 2016. Brasília: Banco do Brasil.

Barcellos, S. B. (2014a). A formulação das políticas públicas para a juventude rural no Brasil: atores e fluxos políticos nesse processo social (Tese de doutorado). Universidade Federal Rural do Rio de Janeiro, Rio de Janeiro.

Barcellos, S. B. (2014b). Desafios para a construção de políticas públicas para a juventude rural. In M. A. Menezes, V. L. Stropasolas \& S. B. Barcellos (Orgs.), Juventude rural e políticas públicas no Brasil (pp. 53-57). Brasília: MDA.

Bianchini, V. (2015). Vinte Anos do PRONAF, 1995-2015: avanços e desafios. Brasília: MDA.

Bourdieu, P. (2011). “Jeunesse” n'est pas qu'un mot. In P. Bourdieu. Questions de sociologie (pp. 143-154). Lonrai: Les Éditons de Minuit.

Brasil. (2006). Decreto $n^{\circ}$ 5.658, de 2 de janeiro de 2006. Promulga a Convenção-Quadro sobre Controle do Uso do Tabaco, adotada pelos países membros da Organização Mundial de Saúde em 21 de maio de 2003 e assinada pelo Brasil em 16 de junho de 2003. Diário Oficial [da] República Federativa do Brasil, Brasília.

Brasil. Ministério do Desenvolvimento Agrário - MDA. (2013). Juventude rural: mais jovens poderão acessar Pronaf. Brasília: MDA.

Brasil. Ministério do Desenvolvimento Agrário - MDA. (2014). Governo Federal facilita acesso da juventude ao crédito rural. Brasília: MDA.

Brasil. (2016b). Decreto $n^{\circ}$ 8.736, de 3 de maio de 2016: institui o plano nacional de juventude e sucessão rural. Diário Oficial [da] República Federativa do Brasil, Brasília.

Brasil. Ministério do Desenvolvimento Agrário - MDA. (2016a). Sistema de Informações Territoriais. Composição Municipal do Território Região Central - RS. Brasília: MDA.

Carneiro, M. J. (2001). Herança e gênero entre agricultores familiares agricultores familiares. Estudos Feministas, 9(2), 22-55.

Castro, E. G. (2005). Entre ficar e sair: uma etnografia da construção da categoria jovem rural (Tese de doutorado). Universidade Federal do Rio de Janeiro, Rio de Janeiro.

Castro, E. G. (2009). Os jovens estão indo embora? Juventude rural e a construção de um ator político. Rio de Janeiro: Mauad X; Seropédica: Edur.

Cellard, C. (2010). A análise documental. In J. Poupart, J. P. Deslauriers, L. H. Groulx, A. Laperrière, R. Mayer \& A. P. Pires. (Orgs.), A pesquisa qualitativa: enfoques epistemológicos e metodológicos (pp. 297316). Petrópolis: Vozes.

Costa, F. L. M., \& Ralisch, R. (2013). A juventude rural do assentamento Florestan Fernandes no município de Florestópolis (PR). Revista de Economia e Sociologia Rural, 51(3), 415-432.

Cover, M. (2014). Os desafios para a construção de políticas públicas para a juventude rural. In M. A. Menezes, V. L. Stropasolas \& S. B. Barcellos (Orgs.), Juventude rural e políticas públicas no Brasil (pp. 53-57). Brasília: MDA.

Escher, F., Schneider, S., Scarton, L.M., \& Conterato, M. A. (2014). Caracterização da pluriatividade e dos plurirrendimentos da agricultura brasileira a partir do Censo Agropecuário 2006. Revista de Economia e Sociologia Rural, 52(4), 643-668.

Feixa, C. P. (2004). A construção histórica da juventude. In A. Caccia-Bava, C. F. Pàmpols, D. I. P. Costa (Orgs.), Jovens na América Latina. São Paulo: Escrituras.

Feixa, C. P. (2006). De jóvenes, bandas y tribus. Barcelona: Ariel.

Gazolla, M., \& Schneider, S. (2013). Qual "fortalecimento" da agricultura familiar? Uma análise do Pronaf crédito de custeio e investimento no Rio Grande do Sul. Revista de Economia e Sociologia Rural, Piracicaba, v. 51, p. 45-68, 2013. 
Gugel, J. T., Giehl, A. L., Araujo, L. A., \& Haverroth, C. (2017). Pronaf Jovem em Santa Catarina: abrangência, limites e desafios. In Anais do $55^{\circ}$ Congresso da Sociedade Brasileira de Economia, Administração e Sociologia Rural (p. 1-15). Brasília: SOBER.

Instituto Brasileiro de Geografia e Estatística - IBGE. (2010). Censo Demográfico 2010. Brasília: IBGE. Recuperado em 27 de maio de 2018, de http://www.ibge.gov.br

Kempfer, F. (2007). Políticas públicas, direitos e participação. In E. G. Castro \& M. J. Carneiro (Orgs.), Juventude rural em perspectiva (pp. 81-85). Rio de Janeiro: Mauad X.

Marin, J. O. B., Schneider, S., Vendruscolo, R., \& Silva, C. B. C. (2012). O problema do trabalho infantil na agricultura familiar: o caso da produção de tabaco em Agudo - RS. Revista de Economia e Sociologia Rural, 50(4), 763-778.

Paulo, M. A. L. (2014). Juventudes rurais do Nordeste: as múltiplas realidades numa região de contrastes. In M. A. Menezes, V. L. Stropasolas \& S. B. Barcellos (Orgs.), Juventude rural e políticas públicas no Brasil. ) p. 234-250). Brasília: MDA.

Picolotto, E. L., \& Marin, J. O. B. (2018). Juventude Rural: estudo na Região Central do Rio Grande do Sul. Rio de Janeiro: Editora Bonecker.

Pires, A. P. (2010). Amostragem e pesquisa qualitativa: ensaio teórico e metodológico. In J. Poupart, J. P. Deslauriers, L. H. Groulx, A. Lapiiière, R. Mayer \& A. P. Pires (Orgs.), A pesquisa qualitativa: enfoques epistemológicos e metodológicos (pp. 154-211). Petrópolis: Vozes.

Schneider, S. (2003a). A pluriatividade na agricultura familiar. Porto Alegre: Ed. da Universidade/UFRGS.

Schneider, S. (2003b). Teoria social, agricultura familiar e pluriatividade. Revista Brasileira de Ciências Sociais, 18(51), 100-122.

Schneider, S., Silva, M. K., \& Marques, P. E. M. (2004). Políticas públicas e participação social no Brasil Rural. Porto Alegre: Ed. da UFRGS.

Spanevello, R. M. (2008). A dinâmica sucessória na agricultura familiar (Tese de doutorado). Universidade Federal do Rio Grande do Sul, Porto Alegre.

Stropasolas, V. L. (2006). O mundo rural no horizonte dos jovens. Florianópolis: Ed. da UFSC.

Urteaga, M. C. P. (2011). La construcción juvenil de la realidad: jóvenes mexicanos contemporáneos. México: Universidad Autónoma Metropolitana, Juan Pablos Editor.

Urteaga, M. C. P., \& Pérez, J. A. (2004). Imagens juvenis do México moderno. In A. Caccia-Bava, C. P. Feixa \& Y. C. Gonzáles (Orgs.), Jovens na América Latina. São Paulo: Escrituras.

Wanderley, M. N. B. (2007). Jovens rurais de pequenos municípios de Pernambuco: que sonhos para o futuro. In M. J. Carneiro \& E. G. Castro (Orgs.), Juventude rural em perspectiva (pp. 35-51). Rio de Janeiro: Mauad X.

Weisheimer, N. (2009). A situação juvenil na agricultura familiar (Tese de doutorado). Universidade Federal do Rio Grande do Sul, Porto Alegre.

Weisheimer, N. (2013). Estudo da situação juvenil na agricultura familiar do recôncavo da Bahia. In Anais do $37^{\circ}$ Encontro Anual da ANPOCS. São Paulo: ANPOCS.

Submetido: $7 /$ Nov./2017

Aceito: 9/Jun./2019

JEL: J71, J78, J88, Q18, R58. 